\title{
Microbiological characteristics of clinical isolates of Cryptococcus spp. in Bahia, Brazil: molecular types and antifungal susceptibilities
}

\author{
C. S. Matos • A. de Souza Andrade • N. S. Oliveira • \\ T. F. Barros
}

Received: 19 April 2011 / Accepted: 5 November 2011 /Published online: 26 January 2012

(C) The Author(s) 2012. This article is published with open access at Springerlink.com

\begin{abstract}
To determine the profiles of susceptibility to antifungal and the genotypes of clinical isolates of Cryptococcus in Bahia, Brazil, 62 isolates were collected from cases of meningitis in the period from 2006 to 2010. Their susceptibilities to fluconazole, itraconazole, amphotericin B and 5-flucytosine were determined by the broth microdilution technique described by the Clinical and Laboratory Standards Institute and genotyping of the URA5 gene was accomplished by restriction fragment length polymorphism. C. neoformans accounted for $79 \%$ of the identified yeast and $C$. gattii represented the remaining $21 \%$. Evaluation of the genotypes determined that $100 \%$ of the C. gattii isolates belong to the VGII
\end{abstract}

C. S. Matos

Graduate Program in Pharmacy, Faculty of Pharmacy, UFBA,

Salvador, Brazil

A. de Souza Andrade

Program for Scientific Initiation, Faculty of Pharmacy, UFBA,

Salvador, Brazil

N. S. Oliveira

Couto Maia Specialized Hospital,

Salvador, Brazil

T. F. Barros

Department of Clinical and Toxicological Analysis,

Faculty of Pharmacy, UFBA,

Salvador, Brazil

T. F. Barros $(\bowtie)$

College of Pharmacy, Federal University of Bahia,

Street Barão de Jeremoabo, University Campus of Ondina,

Ondina, Salvador, Bahia, Brazil CEP 40170-290

e-mail: tfbarros@uol.com.br

T. F. Barros

e-mail: tfbarros@ufba.br genotype, and $98 \%$ of the C. neoformans isolates belong to the VNI genotype. Determination of susceptibility revealed isolates resistant to fluconazole $(4.8 \%)$, 5flucytosine (1.6\%) and amphotericin B (3.2\%); the stratification of sensitivity results for each species showed significant differences in susceptibility to azoles. This study is the first to describe the susceptibility profiles of molecular and clinical isolates of Cryptococcus in Bahia, Brazil. The high percentage of $C$. gattii isolates belonging to the VGII genotype and its lower susceptibility to antifungal agents highlight the importance of knowing which species are involved in cryptococcal infections in northeastern Brazil.

\section{Introduction}

Cryptococcal meningitis, an important opportunistic infection in HIV-positive patients in developing countries, is caused by Cryptococcus spp., which are encapsulated yeasts that are spread worldwide. The genus has two species most commonly associated with infection in humans, Cryptococcus neoformans (serotypes A, D and the AD hybrid; VNI - IV genotypes) and Cryptococcus gattii (serotypes B and C; VGI - IV genotypes), which differ genotypically, phenotypically and epidemiologically [1-3].

Immunocompromised patients are more frequently infected by $C$. neoformans, while $C$. gattii has emerged as an important cause of infection in immunocompetent individuals, as illustrated by the recent outbreak on Vancouver Island (Canada) by the VGII genotype, with molecular evidence of spread to the northwestern United States [4-6]. In Brazil, there are few studies that illustrate the distribution of this genotype [7, 8]. The yeast is 
acquired from the environment, and its tropism for the central nervous system leads to meningitis $[9,10]$. The American Society of Infectious Diseases suggests that the treatment of cryptococcal meningitis be initiated with an induction therapy of amphotericin B alone or combined with 5-flucytosine, followed by consolidation and maintenance therapy with an azole [11].

There are few reports of antifungal resistance in isolates of Cryptococcus [12-14]. Although some authors suggest that it remains stable [15-17], the ARTEMIS global antifungal surveillance study showed increased fungal resistance to fluconazole. In the period from 1997-2000, the rate of resistance to fluconazole was $7.3 \%$; in 2005 2007 , this rate increased to $11.7 \%$, with the highest rates found in Latin America (13.6\%) and Africa (12.4\%) [18]. The authors propose that the increased resistance may be limited to areas where antiretroviral therapy is still not effective, such as Spain [13], Cambodia [12] and Africa $[19,20]$.

Little is known about the frequency and susceptibility profile of Cryptococcus species in northeastern Brazil. Thus, this study aims to determine the antifungal susceptibility profiles and the frequencies of species and genotypes of clinical isolates of Cryptococcus spp. in the state of Bahia in northeastern Brazil.

(a)

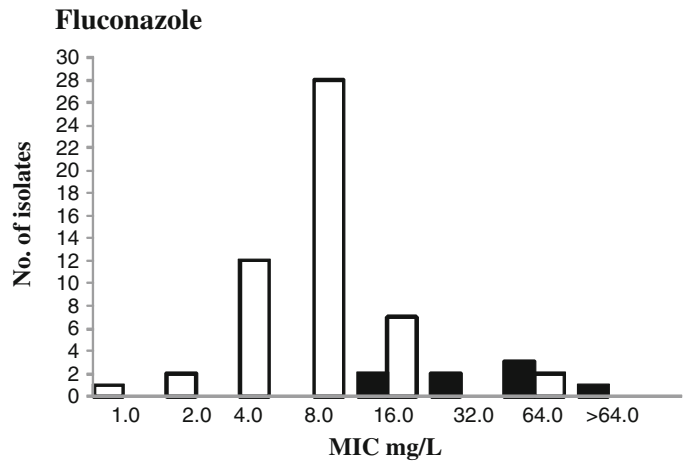

(c)

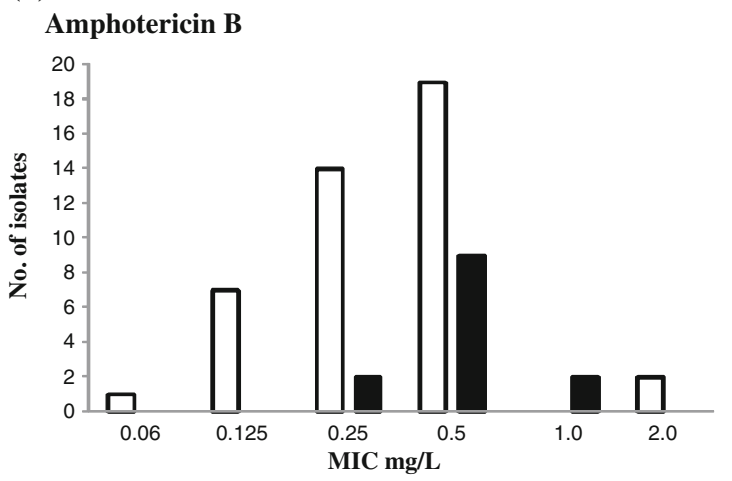

\section{Materials and methods}

Source and identification of clinical isolates

We collected 62 clinical isolates from 62 cases of cryptococcal meningitis diagnosed at the Hospital Couto Maia, Bahia, from 2006 to 2010. After 48 hours of growth on Sabouraud dextrose agar (Acumed, New York, NY), the genus was identified based on the demonstration of typical encapsulated cells in India ink preparations and the development of brown pigmentation on the surface of Niger seed agar; classical biochemical tests were also conducted for the identification of yeasts [21]. The identification of C. neoformans and C. gattii was accomplished using canavanine-glycine-bromothymol blue agar [22]. This study was approved by the ethics committee of the Hospital Couto Maia.

Reference strains

Cryptococcus complex reference strains were kindly provided by the Mycology Laboratory of the Institute of Clinical Research Evandro Chagas - Oswaldo Cruz Foundation and included WM 148 (VNI), WM 626 (VNII), WM 628 (VNII), WM 629 (VNIV), WM 179 (VGI), WM 178 (VGII), WM 161 (VGIII) and WM 779 (VGIV) [23].

(b)

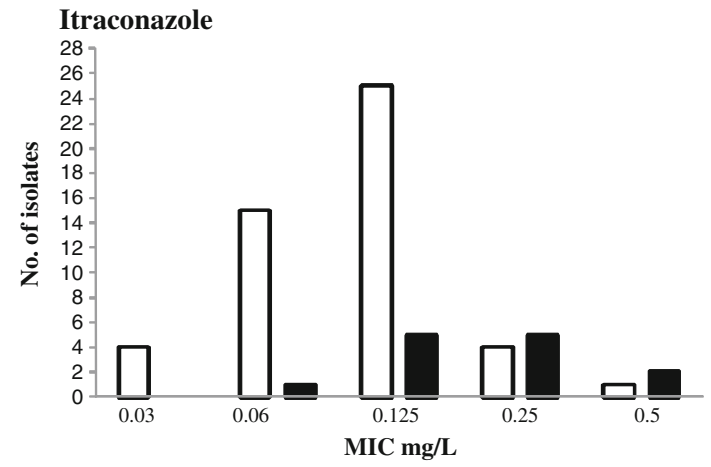

(d)

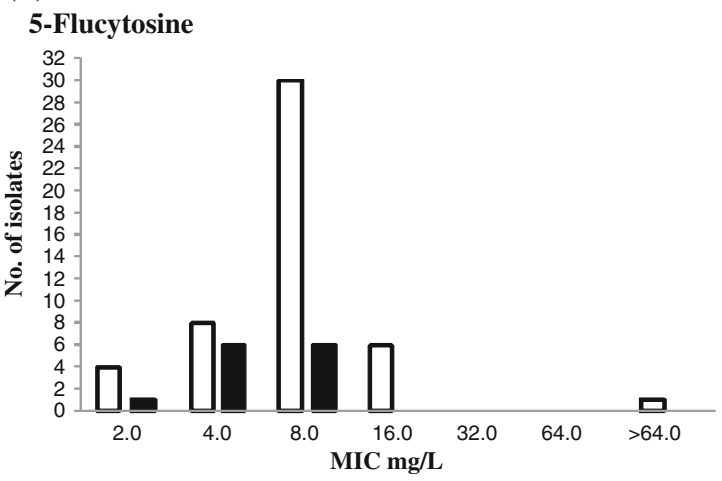

Fig. 1 The distributions of MIC (mg/L) values for fluconazole (a), itraconazole (b), amphotericin B (c) and 5-flucytosine (d) for 62 isolates of Cryptococcus spp. C. neoformans (empty bars) and C. gattii (black bars) 
Table 1 Susceptibility profiles and in vitro activities of antifungal agents against clinical isolates of Cryptococcus spp

$S$ susceptible, $S-D D$ susceptible, dose-dependent, $R$ resistant

\begin{tabular}{|c|c|c|c|c|c|}
\hline \multirow[t]{2}{*}{ Antifungal agent } & \multirow[t]{2}{*}{ Species } & \multicolumn{3}{|c|}{ Susceptibility profile $\%$} & \multirow[t]{2}{*}{$p$ value* } \\
\hline & & $\mathrm{S}$ & S-DD & $\mathrm{R}$ & \\
\hline Fluconazole & $\begin{array}{l}\text { C. neoformans } \\
\text { C. gattii }\end{array}$ & $\begin{array}{l}83.7(41 / 49) \\
38.5(5 / 13)\end{array}$ & $\begin{array}{r}14.3(7 / 49) \\
46(6 / 13)\end{array}$ & $\begin{array}{r}2(1 / 49) \\
15.5(2 / 13)\end{array}$ & 0.013 \\
\hline Itraconazole & $\begin{array}{l}\text { C. neoformans } \\
\text { C. gattii }\end{array}$ & $\begin{array}{l}89.8(44 / 49) \\
46.1(6 / 13)\end{array}$ & $\begin{array}{l}10.2(5 / 49) \\
53.9(7 / 13)\end{array}$ & $\begin{array}{l}0 \\
0\end{array}$ & 0.001 \\
\hline Amphotericin B & $\begin{array}{l}\text { C. neoformans } \\
\text { C. gattii }\end{array}$ & $\begin{array}{r}96(48 / 49) \\
100(13 / 13)\end{array}$ & $\begin{array}{l}0 \\
0\end{array}$ & $\begin{array}{l}4(2 / 49) \\
0\end{array}$ & 0.622 \\
\hline 5-Flucytosine & $\begin{array}{l}\text { C. neoformans } \\
\text { C. gattii }\end{array}$ & $\begin{array}{l}24.5(12 / 49) \\
53.9(7 / 13)\end{array}$ & $\begin{array}{c}7.5(36 / 49) \\
46.1(6 / 13)\end{array}$ & $\begin{array}{l}2(1 / 49) \\
0\end{array}$ & 0.163 \\
\hline
\end{tabular}

Reference strains from the American Type Culture Collection (ATCC) included Candida parapsilosis 22019 and $C$. krusei 6258, which were also used for quality and reproducibility controls during susceptibility testing.

\section{Antifungal susceptibility tests}

The susceptibility tests against fluconazole, itraconazole, amphotericin B and 5-flucytosine (Sigma Aldrich Quimica $\mathrm{SA}$, St. Louis, MO) were performed as described in document M27-A3 of the Clinical and Laboratory Standards Institute (CLSI) [24]. The minimum inhibitory concentrations (MICs) were determined by the lowest antifungal agent concentrations that inhibited 50\% fungal growth compared to the control growth (without antifungal) for fluconazole, itraconazole and 5-flucytosine; the MICs for amphotericin B were determined by the lowest concentrations that inhibited $100 \%$ growth.

\section{DNA extraction}

For the extraction of genomic DNA, the mechanical lysis method was used after digestion of the capsule with urea buffer [25].

Restriction fragment length polymorphism (RFLP) - URA5 gene

RFLP analysis using the URA5 gene was performed as described by Meyer and colleagues (2003) using the primers URA5 (5'ATGTCCTCCCAAGCCCTC GACTCCG3') and SJ01 (5' TTAAGACCTCTGAA CACCGTACTC3') [23]. RFLP patterns were assigned visually by comparing them to the patterns obtained from the standard-type strains (VNI-VNIV and VGI-VGIV).

\section{Statistical analysis}

Statistical analysis was performed by the least squares method using SPSS 17.0 software (SPSS Inc, Chicago, Illinois). Statistical significance was defined at $p<0.05$.

\section{Results}

All yeasts were characterized as belonging to the genus Cryptococcus spp., and there were no biochemical differences among isolates; $79 \%$ (49/62) of the isolates were $C$. neoformans and 21\%(13/62) were C. gattii. The distributions of the MIC values of the 62 Cryptococcus spp., separated by species, to the antifungals tested are shown in Fig. 1. The antifungal susceptibility profiles are summarized in Table 1, showing isolates of $C$. neoformans that were resistant to fluconazole, amphotericin B and 5flucytosine and C. gattii isolates that were significantly resistant to fluconazole.

The URA5 gene RFLP analysis revealed that 98\% (48/ 49) of isolates of $C$. neoformans presented the profile of the molecular genotype VNI and 2\% (1/49) of genotype VNII,

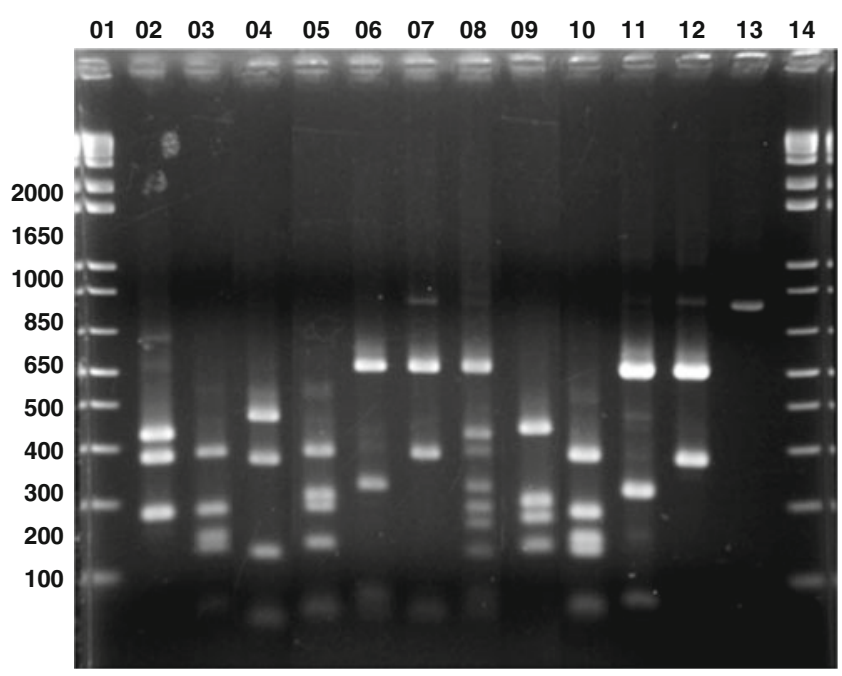

Fig. 2 Representative RFLP profiles of the URA5 genes from Cryptococcus spp. obtained by double-digestion with HhaI and Sau96I. Lanes 1 and 14 are the molecular markers; lanes 2, 3, 4, and 5 are genotypes VGI, VGII, VGIII and VGIV, respectively; lanes $6,7,8$, and 9 are genotypes VNI, VNII, VNII and VNIV, respectively; lane 10 is the clinical isolate of $C$. gattii; lanes 11 and 12 are clinical isolates of C. neoformans; lane 13 is the URA5 gene amplified product 
while $100 \%(13 / 13)$ of isolates of $C$. gattii showed VGII genotype profile (Fig. 2).

\section{Discussion}

The epidemiology of Cryptococcus has been widely studied around the world, but in Brazil, information regarding the distribution of species is still fragmentary and incomplete, reflecting only differences in frequency. Cryptococcosis caused by $C$. neoformans is an important cause of morbidity and mortality in immunocompromised individuals worldwide, but the number of published reports of infection by $C$. gattii in patients without immunosuppression is increasing $[3-5,26]$.

C. gattii was initially considered to be restricted to tropical and subtropical Australia, Southeast Asia and some African regions. Currently, however, it is expanding to the northwest Pacific and North America, which suggests it is adapting to a new climatic niche or that global warming may provide favorable conditions for its growth [5, 27, 28]. In Brazil, the analysis of Cryptococcus spp. isolates from various regions has shown that $C$. gattii is significantly more prevalent in the north-northeast of the country and that C. neoformans is more prevalent in the south-southeast of the country; however, there are few studies in the northnortheast that report the distributions of these pathogens [29].

Santos and colleagues (2008) analyzed the distribution of species in 56 isolates from 43 patients with meningitis in the state of Pará and identified a frequency of $35.7 \%(20 /$ 56) for $C$. gattii infection [30]. In the southeast, all isolates from different areas of São Paulo belonged to C. neoformans [31]. However, Almeida and colleagues (2007) analyzed 83 samples from 38 patients and found only four isolates of C. gattii from only one patient [32]. In Minas Gerais, $11.4 \%$ of 35 isolates belonged to the species $C$. gattii [33]. In the state of Mato Grosso, in the Midwest, $16.6 \%$ of 26 samples of 26 cases of cryptococcosis were $C$. gattii isolates [34]. These results reveal a high number (13) of isolates of $C$. gattii (21\%) compared with other studies [30-34] and suggest that Bahia is an important source of infection by $C$. gattii.

Genotypic determination revealed a predominance of the VNI genotype among $C$. neoformans isolates, which have been frequently reported in various regions of the world [35-40]. All C. gattii isolates belonged to the VGII genotype. This genotype was reported as the causal agent of the cryptococcosis outbreak that occurred on Vancouver Island (BC, Canada) $[4,41]$. This genotype has also been reported in Brazil [7, 8] demonstrating its potential to cause severe disease in immunocompetent hosts, as it was recognized as the main agent of a primary cryptococcosis endemic in the north $[29,30]$.
The determination of susceptibility profiles revealed the presence of antifungal-resistant $C$. neoformans isolates. Antifungal resistance is among the factors that can contribute to treatment failure because previous exposure to a risk factor often leads to resistance [42, 43]. Our findings are consistent with authors who suggest that there are differences between C. neoformans and C. gattii sensitivities [44-46], although others disagree $[14,47,48]$. It is known that an infection caused by $C$. gattii has a less favorable response to antifungal therapy and a relatively worse prognosis compared to infection by $C$. neoformans $[49,50]$; however, the mechanisms underlying this difference are not clear.

\section{Conclusion}

This study is the first to describe the susceptibility profiles of molecular and clinical isolates of Cryptococcus in Bahia, Brazil. The high percentage of isolates from the $C$. gattii genotype VGII, in addition to its lower susceptibility to antifungal agents, highlights the importance of knowing the species involved in cryptococcal infection in this state. Surveillance studies are needed to elucidate the environmental niche of this yeast and to monitor trends in antifungal susceptibility and the distribution of species in Bahia, Brazil.

Acknowledgements We thank the Mycology Laboratory of the Institute of Clinical Research Evandro Chagas - Oswaldo Cruz Foundation (FIOCRUZ) - Rio de Janeiro, Brazil for the standard isolates of Cryptococcus used in this study.

We also thank the Foundation for Research of the State of Bahia and the Coordination for the Improvement of Higher Education Personnel for the financial support for this project.

Open Access This article is distributed under the terms of the Creative Commons Attribution Noncommercial License which permits any noncommercial use, distribution, and reproduction in any medium, provided the original author(s) and source are credited.

\section{References}

1. Casadevall A, Perfect JR (1998) Cryptococcus neoformans. ASM Press, Washington

2. Kwon-Chung KJ, Varma A (2006) Do major species concepts support one, two or more species within Cryptococcus neoformans? FEMS Yeast Res 6:574-587

3. Park JB, Wannemuehler KA, Marston NG, Pappas PG, Chiller TM (2009) Estimation of the current global burden of cryptococcal meningitis among person living with HIV/AIDS. AIDS 23:525-530

4. Kidd SE, Hagen F, Tscharke RL, Huynh M, Bartlett KH, Fyfe M (2004) A rare genotype of Cryptococcus gattii caused the cryptococcosis outbreak on Vancouver Island (British Columbia Canada). Proc Natl Acad Sci USA 101:17258-17263

5. Byrnes EJ III, Bildfell R, Frank SA, Mitchell TG, Marr K, Heitman J (2009) Molecular evidence that the Vancouver Island Cryptococcus gattii outbreak has expanded into the United States Pacific Northwest. J Infect Dis 199:1081-1086 
6. Lockhart SR, Harris J (2010) Cryptococcus gattii: clinical importance and emergence in North America. Curr Fungal Infect Rep. doi:10.1007/s12281-010-0021-y

7. Trilles L, Lazéra MS, Wanke B, Oliveira RV, Barbosa GG, Nishikawa MM, Morales BP, Meyer W (2008) Regional pattern of the molecular types of Cryptococcus neoformans and Cryptococcus gattii in Brazil. Memórias do Instituto Oswaldo Cruz 103:455-462

8. Costa SPSE, Lazéra MS, Santos WRA, Morales BP, Bezerra CCF, Nishikawa MM, Barbosa GG, Trilles L, Nascimento JLM, Wanke B (2009) First isolation of Cryptococcus gattii molecular type VGII and Cryptococcus neoformans molecular type VNI from environmental sources in the city of Belém, Pará, Brazil. Memórias do Instituto Oswaldo Cruz 104:662-664

9. Alspaugh JA, Perfect JR (2002) Cryptococcal meningitis. Curr Treat Opin Infect Dis 4:75-80

10. Lin X, Heitman J (2006) The biology of the Cryptococcus neoformans species complex. Annu Rev Microbiol 60:69-105

11. Perfect JR, Dismukes WE, Dromer F, Goldman DL, Graybill JR, Hamill RJ, Harrison TS, Larsen RA, Lortholary O, Nguyen M, Pappas PG, Powderly WG, Singh N, Sobel JD, Sorrell TC (2010) Clinical practice guidelines for the management of Cryptococcal disease: 2010 - infectious diseases society of America. Clin Infect Dis 50:291-322

12. Chandenier J, Adou-Bryn KD, Douchet C, Sar B, Kombila M, Swinne D, Therizol-Ferly M, Buisson Y, Richard-Lenovle D (2004) In vitro activity of amphotericin $\mathrm{B}$, fluconazole, and voriconazole against 162 Cryptococcus neoformans isolates from Africa and Cambodia. Eur J Clin Microbiol Infect Dis 23:506-508

13. Perkins A, Gomez-Lopez A, Mellado E, Rodriguez-Tudela JL, Cuenca-Estrella M (2005) Rates of antifungal resistance among Spanish clinical isolates of Cryptococcus neoformans var. neoformans. J Antimicrob Chemother 56:1144-1147

14. Thompson GR III, Wiederhold NP, Fothergill AW, Vallor AC, Wickes BL, Patterson TF (2009) Antifungal susceptibilities among different serotypes of Cryptococcus gattii and Cryptococcus neoformans. Antimicrob Agents Chemother 53:309-311

15. Brandt ME, Pfaller MA, Hajjeh RA, Hamill RJ, Pappas PG, Reingold AL, Rimland D, Warnock DW, Cryptococcal Disease Active Surveillance Group (2001) Trends in antifungal drug susceptibility of Cryptococcus neoformans isolates in the United States: 1992 to 1994 and 1996 to 1998. Antimicrob Agents Chemother 45:3065-3069

16. Pfaller MA, Messer SA, Boyken L, Rice C, Tendolkar S, Hollis RJ, Doern GN, Diekema DJ (2005) Global trends in the antifungal susceptibility of Cryptococcus neoformans (1990 to 2004). J Clin Microbiol 43:2163-2167

17. Aller AI, Claro R, Castro C, Serrano C, Colom MF, MartinMazuelos E (2007) Antifungal susceptibility of Cryptococcus neoformans isolates in HIV-infected patients to fluconazole, itraconazole, and voriconazole in Spain: 1994-1996 and 19972005. Chemotherapy 53:300-305

18. Pfaller AM, Diekema DJ, Gibbs DL, Newell VA, Bijie H, Dzierzanowska D, Klimko NN, Letscher-Bru V, Lisalova M, Muehlethaler K, Rennison C, Zaidi M, and the Global Antifungal Surveillance Group (2009) Results from the ARTEMIS DISK Global Antifungal Surveillance Study, 1997 to 2007: 10.5-year analysis of susceptibilities of noncandidal yeast species to fluconazole and voriconazole determined by CLSI standardized disk diffusion testing. J Clin Microbiol 47:117-123

19. Bicanic T, Wood R, Bekker LG, Darder M, Meintjes G, Harrison TS (2005) Antiretroviral roll-out, antifungal roll-back: access to treatment for Cryptococcal meningitis. Lancet Infect Dis 5:530-531

20. Bii CC, Makimura K, Abe S, Taguchi H, Mugasin OM, Revathi G, Wamae N, Kamiya S (2006) Antifungal drug susceptibility of Cryptococcus neoformans from clinical sources in Nairobi, Kenya. Mycoses 50:25-30
21. Kwon-Chung KJ (1975) A new genus, Filobasidiella, the perfect state of Cryptococcus neoformans. Mycol 67:1197-1200

22. Kwon-Chung KJ, Polacheck I, Bennett JE (1982) Improved diagnostic medium for separation of Cryptococcus neoformans var. neoformans (serotypes A and D) and Cryptococcus neoformans var. gattii (serotypes B and C). J Clin Microbiol 15:535-537

23. Meyer W, Castaneda A, Jackson S, Huynh M, Castaneda E, the Ibero American Cryptococcal Study Group (2003) Molecular typing of IberoAmerican Cryptococcus neoformans isolates. Emerg Infect Dis 9:189-195

24. Clinical Laboratory Standards Institute (CLSI) (2008) Reference method for broth dilution antifungal susceptibility testing of yeasts; approved standard, third edition. CLSI document M27A3. Wayne, PA

25. Bolano A, Stinchi S, Preziosi R, Bistoni F, Allegrucci M, Baldelli F, Martini A, Cardinali G (2001) Rapid methods to extract DNA and RNA from Cryptococcus neoformans. FEMS Yeast Res $1: 221-224$

26. MacDougall L, Fyfe M, Romney M, Starr M, Galanis E (2011) Risk factors for Cryptococcus gattii infection, British Columbia, Canada. Emerg Infect Dis 17:193-199

27. Centers for Disease Control and Prevention (CDC) (2010) Emergence of Cryptococcus gattii-Pacific Northwest, 20042010. MMWR Morb Mortal Wkly Rep 59:865-868

28. Lester SJ, Malik R, Bartlett KH, Duncan CG (2011) Cryptococcosis; update and emergence of Cryptococcus gattii. Vet Clin Pathol 1-14

29. Nishikawa MM, Lazéra MS, Barbosa GG, Trilles L, Balassiano BR, Macedo RCL, Bezerra CCF, Pérez MA, Cardarelli P, Wanke B (2003) Serotyping of 467 Cryptococcus neoformans isolates from clinical and environmental sources in Brazil: analysis of host and regional patterns. J Clin Microbiol 41:73-74

30. Santos WR, Meyer W, Wanke B, Costa SPSE, Trilles L, Nascimento JLM, Medeiros R, Morales BP, Bezerra CCF, Macêdo RCL, Ferreira SO, Barbosa GG, Perez MA, Nishikawa MM, Lazéra MS (2008) Primary endemic Cryptococcus gattii by molecular type VGII in the state of Pará, Brazil. Memórias do Instituto Oswaldo Cruz 103:813-818

31. Matsumoto MT, Fusco-Almeida AM, Bazea LC, Melhem MSC, Mendes Ginnini MJS (2007) Genotyping, serotyping and determination of mating-type of Cryptococcus neoformans clinical isolates from São Paulo state, Brazil. Revista do Instituto de Medicina Tropical de São Paulo 49:41-47

32. Almeida AMF, Matsumoto MT, Baeza LC, Oliveira e Silva RB, Kleiner AAP, Melhem MSC, Giannini MJSM, the Laboratory Group on Cryptococcosis (2007) Molecular typing and antifungal susceptibility of clinical sequential isolates of Cryptococcus neoformans from Sao Paulo State, Brazil. FEMS Yeast Res $7: 152-164$

33. Silva PR, Rabelo RAS, Terra APS, Teixeira DNS (2008) Susceptibility to antifungal agents among Cryptococcus neoformans varieties isolated from patients at a university hospital. Revista da Sociedade Brasileira de Medicina Tropical 41:158-162

34. Favalessa OC, Ribeiro LC, Tadano T, Fontes CJF, Dias FB, Coelho BPA, Hahn RC (2009) First description of phenotypic profile and in vitro drug susceptibility of Cryptococcus spp. yeast isolated from HIV-positive and HIV-negative patients in State of Mato Grosso. Revista da Sociedade Brasileira de Medicina Tropical 42:661-665

35. Casali AK, Goulart L, Silva LK Rosa e, Ribeiro AM, Amaral AA, Alves SH, Schrank A, Meyer W, Vainstein H (2003) Molecular typing of clinical and environmental Cryptococcus neoformans isolates in the Brazilian state of Rio Grande do Sul. FEMS Yeast Res 3:405-415

36. Igreja RP, Lazera MS, Wanke B, Galhardo MC, Kidd SE, Meyer W (2004) Molecular epidemiology of Cryptococcus neoformans 
isolates from AIDS patients of the Brazilian city, Rio de Janeiro. Med Mycol 42:229-238

37. Sriburee P, Khayhan S, Khamwan C, Panjaisee S, Tharavichitkul P (2004) Serotype and PCR-fingerprints of clinical and environmental isolates of Cryptococcus neoformans in Chiang Mai, Thailand. Mycopatologia 158:25-31

38. Morera-López Y, Torres-Rodríguez JM, Jiménez-Cabello T, BaróTomás T, Alía-Aponte C, Lázera MS (2005) DNA fingerprinting pattern and susceptibility to antifungal drugs in Cryptococcus neoformans variety grubii isolates from Barcelona city and rural environmental samples. Mycopathologia 160:9-14

39. Chen M, Li CY, Wu SX, Tang XT, Feng B, Yao ZR, Pan WH, Liao HQ, Quan ZX (2010) Molecular epidemiology of Cryptococcus neoformans species complex isolates from HIVpositive and HIV-negative patients in southeast China. Front Med China 4:117-126

40. Choi YH, Ngamskulrungroj P, Varma A, Sionov E, Hwang SM, Carriconde F, Meyer W, Litvintseva AP, Lee WG, Shin JH, Kim EC, Lee KW, Choi TY, Lee YL, Kwon-Chung KJ (2010) Prevalence of the VNIc genotype of Cryptococcus neoformans in non-HIV-associated cryptococcosis in the Republic of Korea. FEMS Yeast Res 10:769-778

41. Stephen C (2002) Multispecies outbreak of cryptococcosis on southern Vancouver Island, British Columbia. Can Vet J 43:792794

42. Kanafani ZA, Perfect JR (2008) Resistance to antifungal agents: mechanisms and clinical impact. Clin Infect Dis 46:120-128

43. Pemán J, Cantón E, Espinel-Ingroff A (2009) Antifungal drug resistance mechanisms. Expert Rev Anti-Infect Ther 7:453-460
44. Gomes-Lopez A, Zaragoza O, Dos Anjos M, Melhem MC, Rodriguez-Tudela JL, Cuenca-Estrella M (2008) In vitro susceptibility of Cryptococcus gattii clinical isolates. Clin Microbiol Infect 14:716-730

45. Khan ZU, Randhawa HS, Chehadeh A, Kowshik T, Chandy R (2009) Cryptococcus neoformans serotype A and Cryptococcus gattii serotype B isolates differ in their susceptibilities to fluconazol and voriconazol. Int J Antimicrob Agents 33(6):559563. doi:10.1016/j.ijantimicag.2008.11.007

46. Torres-Rodríguez JM, Alvarado-Ramírez E, Murciano F, Sellart M (2008) MICs and minimum fungicidal concentrations of posaconazole, voriconazole and fluconazole for Cryptococcus neoformans and Cryptococcus gattii. J Antimicrob Chemother 62:205-206

47. Calvo BM, Colombo AL, Fischman O, Santiago A, Thompson L, Lazera M, Telles F, Fukushima K, Nishimura K, Tanaka R, Myiajy M, Moretti-Branchini ML (2001) Antifungal susceptibilities, varieties, and electrophoretic karyotypes of clinical isolates of Cryptococcus neoformans from Brazil, Chile, and Venezuela. J Clin Microbiol 39:2348-2350

48. Moraes EMP, Prímola NS, Hamdan JS (2002) Antifungal susceptibility of clinical and environmental isolates of Cryptococcus neoformans to four antifungal drugs determined by two techniques. Mycoses 46:164-168

49. Speed B, Dunt D (1995) Clinical and host differences between infections with the two varieties of Cryptococcus neoformans. Clin Infect Dis 21:28-34

50. Drew RH, Townsend ML (2010) Antifungal drug resistance: clinical relevance and impact of antifungal drug use. Curr Fungal Infect Rep 4:129-136 